\begin{tabular}{|c|c|c|}
\hline $\begin{array}{l}\text { PKS } \\
\text { PUBLIC } \\
\text { KNDOLEDGE } \\
\text { PROJECT }\end{array}$ & $\begin{array}{c}\text { REVISTA DE GEOGRAFIA } \\
\text { (RECIFE) } \\
\text { http://www.revista.ufpe.br/revistageografia }\end{array}$ & $\begin{array}{l}\text { OJS } \\
\text { OPEN } \\
\text { JOUNAL } \\
\text { SYSTEMS }\end{array}$ \\
\hline
\end{tabular}

\title{
A CARTOGRAFIA RACIAL DE GOIÂNIA: UMA POSSIBILIDADE METODOLÓGICA
}

\author{
Danilo Cardoso Ferreira ${ }^{1}$, Alex Ratts ${ }^{2}$ \\ ${ }^{1}$ Universidade Estadual de Campinas. E-mail: prof.daniloueg@gmail.com \\ ${ }^{2}$ Universidade Federal de Goiás. E-mail: alex.ratts@gmail.com
}

Artigo recebido em 20/02/2017 e aceito em 26/04/2018

\begin{abstract}
RESUMO
O objetivo deste trabalho é apresentar uma possibilidade metodológica da cartografia racial para estudos urbanos na geografia. O exemplo que se utilizou é da cidade de Goiânia buscando entender o lugar dos grupos raciais negros e brancos neste espaço e em seguida, analisar como o processo de segregação racial pode ser entendido a partir da representação cartográfica, para então, problematizar e analisar se existe uma diferenciação com relação ao uso e ocupação dos sujeitos na metrópole não apenas por grupos ou classes diferentes economicamente como também por diferenças raciais. A análise da pesquisa nos apresenta espaços homogêneos de "classe média alta" e "classe alta" em locais que chamamos de espaços brancos, ou seja, com concentração de grupos brancos. E também em regiões periféricas predominantemente com populações de "classe baixa" e "classe extremamente pobre" como concentrações de populações negras. Essa é uma cartografia racial que apontamos como a possibilidade de análise de reprodução e representação das cidades desiguais e segregadas, como o caso de Goiânia.
\end{abstract}

Palavras-chave: Cartografia Racial. Relações Raciais. Segregação Racial.

\section{THE RACIAL CARTOGRAPHY OF GOIÂNIA CITY: A METHODOLOGICAL POSSIBILITY}

\begin{abstract}
The objective of this work is to present a methodological possibility of the racial cartography for urban studies in geography. The example that was used is from the city of Goiânia trying to understand the place of black and white racial groups in this space and, after that, to analyze how the process of racial segregation can be understood from the cartographic representation, and then, to question and analyze whether there is a differentiation in relation to the use and occupation of the subjects in the metropolis not only by different groups or classes economically but also by racial differences. The analysis of the research presents us homogeneous spaces of "upper middle class" and "upper class" in places that we call white spaces, that is, with concentration of white groups. And also, in peripheral regions predominantly with populations of "lower class" and "extremely poor class" as concentrations of black populations. This is a racial cartography that we point out as the possibility of analysis of reproduction and representation of the unequal and segregated cities, as the case of Goiânia.
\end{abstract}

Keywords: Racial Cartography. Racial Relations. Racial Segregation. 


\section{INTRODUÇÃO}

A Geografia dentro de suas diferentes leituras e análises de fenômenos espaciais, territoriais, regionais tem contribuído com diversas possibilidades e leituras a partir de um mundo que cotidianamente se transforma. Essas transformações geram desafios imensos para as ciências, pois as ferramentas de análises, métodos e olhares acerca dos fenômenos sociais precisam estar atentas para que suas respectivas compreensões possam ser coerentes com as realidades da natureza pesquisada.

Nesse sentido, exige-se novos padrões de observação dos pesquisadores para os objetos e fenômenos de estudos, inclusive no padrão de escolha de métodos e literatura que definem correntes filosóficas específicas que não correspondem e não contribuem com as realidades pesquisadas. Os estudos de cartografia têm buscado identificar e apresentar, por meio de suas leituras e análises espaciais, diversas realidades e temáticas. As pesquisas, especificamente sobre análises cartográficas, tanto de questões agrárias, ambientais, urbanas, étnico/raciais, dentre outras, têm sido crescentes. Esse trabalho busca apontar uma possibilidade de leitura da cartografia para entender o que não está tão explícito para a compreensão da sociedade acadêmica, intelectual e outras realidades dos grupos sociais nas cidades brasileiras a partir da questão racial. É possível evidenciar as análises sobre os estudos de segregação a partir da variável racial em representações cartográficas que têm sido potencializadas a partir de grupos e movimentos que buscam evidenciar algo que está velado nos estudos das ciências humanas.

Em consonância a isso, a problematização que se faz, nesta pesquisa, é a seguinte: até que ponto as verificações feitas pelos pesquisadores das diversas temáticas dentro da cartografia evidenciam e representam a realidade dos sujeitos cartografados? Será que o cotidiano pode ser expresso pela representação cartográfica? E como tem sido feito o debate sobre as novas cartografias?

Portanto, o objetivo deste trabalho é apontar alguns trabalhos que avançaram sobre as representações cartográficas que descontroem a ideia de uma cartografia cartesiana que não inclui os debates sociais e raciais (HENRIQUES, 2001; TELLES, 2003; GARCIA, 2006). Além de apresentar uma experiência cartográfica que propõe uma compreensão econômica, social e racial da cidade de Goiânia (GO). 


\title{
CARTOGRAFIA(S)
}

Antes de apresentar os trabalhos de representação cartográfica com diferentes técnicas e metodologias, temos que conceituar o que é a cartografia para depois avançarmos e dizer quais as possibilidades de se utilizá-la para pesquisas e levantamentos de fenômenos sociais, espaciais. A cartografia como técnica de produzir mapas tem sua função de transpor as formas espaciais do plano real para um plano bidimensional, usando como procedimentos a análise, compreensão e a representação do espaço como concebidas pelo mapeador, cartógrafo, geógrafo, informando o que é de seu interesse.

O mapa como produto da cartografia se torna uma linguagem visual textual capaz de representar ou até mesmo silenciar certos fenômenos. Acerca disso, Harley (2009) acrescenta que

\begin{abstract}
Os "silêncios" dos mapas são um conceito central em toda argumentação concernente à influência de suas mensagens políticas ocultas. Afirma-se aqui que, assim como certos exemplos de escritas ou de falas, os mapas exercem uma influência social, tanto por suas omissões quanto pelos elementos que elas representam e valorizam (HARLEY, 2009, p. 13).
\end{abstract}

Os silenciamentos podem ocultar evidências tanto quanto podem representar as escolhas políticas com relação ao objetivo do mapa, o qual pode exercer influências políticas e sociais, e são essas questões que o autor indica como o "poder" de representação de "um mundo socialmente construído" (HARLEY, 2009). A importância dos mapas se deve ao poder de suas representações acerca dos mundos sociais (HARLEY, 2009). Não basta entender somente o passado, mas o presente também. Martinelli (1999, p. 8) acrescenta as dimensões de saber, poder e cultura de um mapa:

Os mapas, junto a qualquer cultura, sempre foram, são e serão formas de saber socialmente construídos; portanto, uma forma manipulada do saber. São imagens carregadas de julgamento de valor. Não há nada inerte e passivo em seus registros. Como linguagem, os mapas conjugam-se com a prática histórica, podendo revelar diferentes visões de mundo. Carregam, outrossim, um simbolismo que pode estar associado ao conteúdo neles representado. 
Os mapas são formas de saber socialmente construídas, apesar das dificuldades que as pessoas têm em tratar e analisar suas informações. Théry (2006, p. 74) complementa mencionando que o "mapa não é simplesmente um elemento, pois antes de tudo é um instrumento de pesquisa que pode revelar as estruturas profundas de um território”. Assim, um dos princípios básicos da cartografia é a comunicação e a orientação dos objetos e fenômenos (MATIAS, 1996), além de que a cartografia serve como forma de saber espacial, conforme afirma Harley.

[...] ainda que os mapas estejam há muito tempo no centro dos discursos sobre a geografia, raramente eles são lidos como textos "profundos "ou como formas de saber socialmente construídas. "A interpretação dos mapas “implica habitualmente o estudo de suas "características geográficas" sem indicar como, enquanto forma manipulada do saber, eles contribuíram para moldar estas características (2009, p. 1).

Porém, mais do que isso, "pode ser também uma forma de conhecimento e uma forma de poder" (HARLEY, 2009, p. 3). É importante considerar, consoante ao que descreve Martinelli (2005), que antes do fim do Século XVIII, a cartografia ignorava totalmente as questões demográficas e econômicas, era um saber/fazer mais estratégico do ponto de vista dos grupos dominantes do Estado.

Desse modo, o mapa se torna um instrumento estratégico de poder, para o saber e conhecimento, por revelar as informações presentes ou ausentes no território, espaço, lugar, região, paisagem e espaços urbanos. Santos R. (2010, p. 143) afirma ser o mapa um instrumento de análise fundamental não só do geógrafo, mas também de todo profissional que se propõe a entender o espaço:

Além dos conceitos e categorias fundamentais de análise do espaço, temos que destacar que os mapas também são poderosos instrumentos de construção de visões de mundo e de posição no mundo. O que eles mostram e o que deixam de mostrar são critérios de verdade, de construção de existências e não-existências. Se reconhecer, e a forma como se é representado e se é reconhecido num mapa também é instrumento poderoso de construção de posturas e tomada de posições. 
O mapa pode ser uma ferramenta de ideologias, de resistências como processo formador de reconhecimento e de tomada de posições políticas, e sobre a cartografia apresentam-se diversas perspectivas; a saber: a aplicada aos conhecimentos do Sensoriamento Remoto (ROSA, 2005), a escolar (ALMEIDA, 2013), a histórica (COSTA \& SANTOS, M. 2010), a de dados de população (ZELINSKY, 1969), a de mapas mentais (RICHTER, 2011), de uso da terra (RIBEIRO \& WALTER, 2008), a turística (OLIVEIRA, 2008), a climatológica (OLIVEIRA \& NASCIMENTO, 2011), a ambiental (ALONSO, 2002), as disputas cartográficas e territoriais (ACSELRAD, 2008), a racial (TELLES, 2003; GARCIA, 2006; CAMPOS, 2006; FRANÇA, 2010; PAIXÃO, 2013), e a étnica (ANJOS, 2006). Dentre todas essas perspectivas cartográficas que buscam, a partir dos fenômenos espaciais, representar os seus objetos e estudos, pretende-se evidenciar a cartografia racial.

Os elementos que são mapeados podem também valorizar o mapa como fonte de informação, de realidades grafadas no espaço, nas cidades. No caso da cidade de Goiás, antiga capital do estado, há uma pesquisa produzida por Brandão (1977), por meio dela ele apresenta uma cartografia racial que discute o lugar do negro, hostilizado na periferia, com baixa infraestrutura urbana, situado em um local de populações de classe pobre (figura 1).

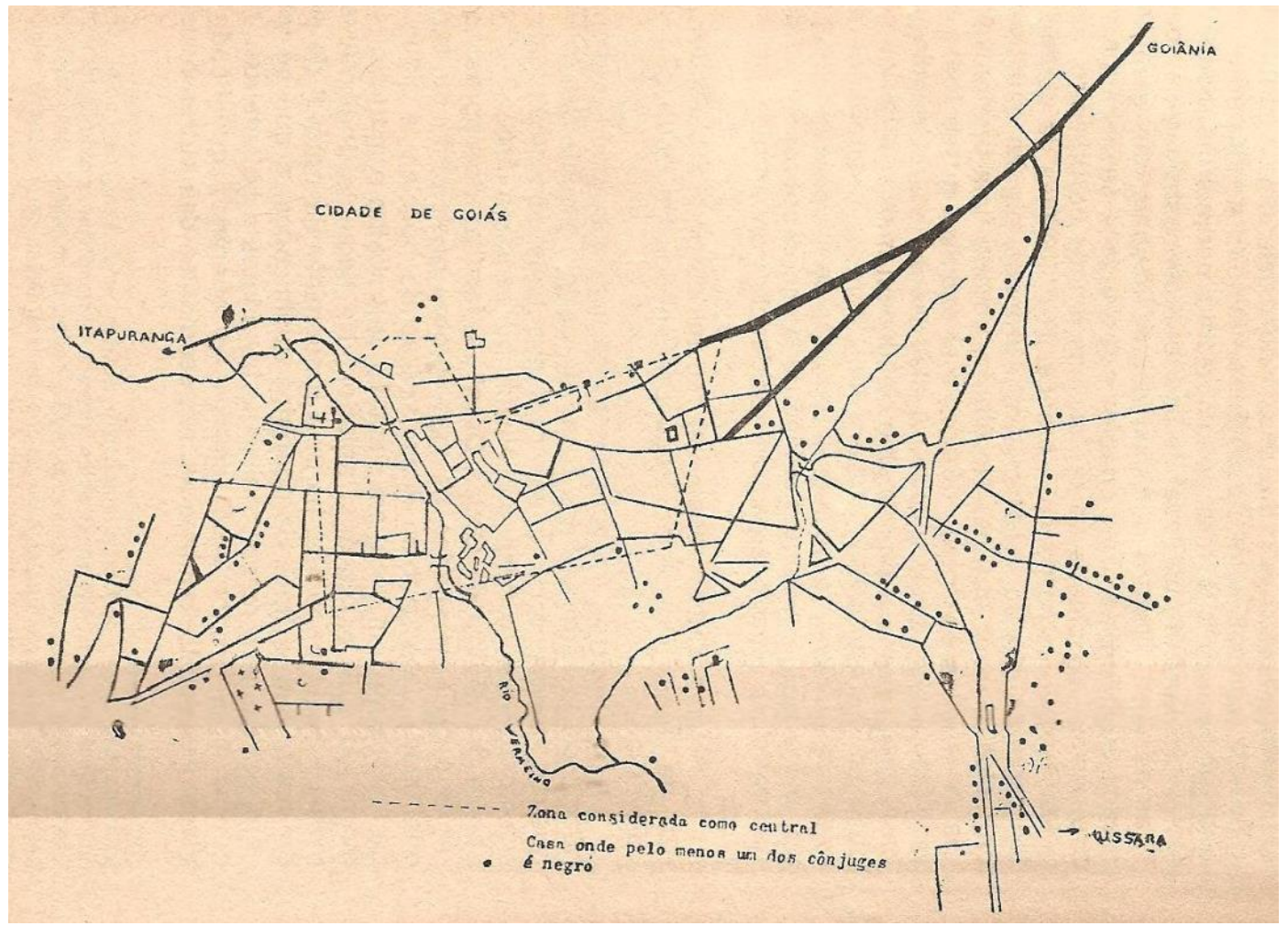

Figura 1. A localização dos domicílios de famílias negras na cidade de Goiás, em 1975.

Fonte: Brandão (1977, p. 76). 
As informações pontuais da figura 1 são os domicílios de famílias negras na cidade de Goiás e a área pontilhada no mapa é a área central. A problematização que Brandão (1977) traz é que além de "peão", "o negro", na cidade de Goiás, poderia ascender no máximo à condição de gari, mestre de obras ou empregado dos comércios locais, tal como em olarias e outros. $\mathrm{O}$ ápice para o negro era a ascensão à condição de soldado da polícia militar. Percebese que o lugar do negro na cidade estava condicionado a sua cor, as famílias negras eram concentradas à margem, na periferia da cidade.

O lugar de o negro viver e morar nas cidades brasileiras, conforme pode ser apontado, é uma regra e um padrão lógico não somente pelo uso, mas também pelo racismo urbano que está velado como um construto social que, para as famílias negras, se tornam barreiras sociais, muros e divisões do direito à cidade. Diante disso, os mapas trazem uma possibilidade de compreensão e ação para os movimentos sociais e culturais, para reexistir e repensar a lógica do viver à margem e na margem das nossas cidades. Isso é presente nos mapeamentos de trabalho escravo no Brasil contemporâneo feito por Théry (2006), de territórios de quilombos realizados por Anjos (2006) e de Garcia (2006) sobre a segregação em Salvador e Rio de Janeiro.

Telles (2003) pondera que a cartografia contribui para a atuação política do movimento negro no Brasil ao representar como a produção capitalista em metrópoles brasileiras segregam os grupos sociais, em especial a população negra, com base nos dados em amostragem do IBGE, do censo de 2000. Efeito semelhante resulta do trabalho de Henriques (2001), cujos indicadores discutem as desigualdades sociais, particularmente as educacionais no Brasil. Telles (2003), Garcia (2006) e França (2010) trabalham com cartografias digitais concebidas a partir de índices matemáticos e estatísticos, apontando que o Brasil é um país de diferenças e desigualdades econômicas, sociais e raciais, sobretudo nas áreas urbanas.

França (2010), além de fazer uma releitura da segregação urbana no Brasil, faz um trabalho cartográfico com embasamento teórico na discussão racial para a capital paulista, utilizando a base de dados do IBGE (2000), por amostragem. O autor utiliza, assim como Telles (2003), os indicadores sociais de renda, alfabetização, saneamento básico, incluindo o bem-estar social e equipamentos públicos, elementos que se interseccionam com a problematização racial. Anjos (2006), ao cartografar os territórios quilombolas no Brasil, procura evidenciar a importância de entender a relação dos povos africanos para a construção do território brasileiro. 
Rios Neto \& Riani (2009) constroem uma cartografia racial de regiões metropolitanas ao apontarem que a distribuição da população branca e negra está associada à variável renda, o que resulta na distribuição da população negra, comumente em áreas com maioria pobre, enquanto a população com maior acesso à riqueza, em sua maioria, é caracterizada de branca. A pesquisa mostra espaços que a priori deveriam ser públicos, não são identificados somente por classes econômicas, mas por hierarquias raciais em espaços que deveriam ser, a princípio, abertos a todos os segmentos. Os autores utilizaram dados do censo do IBGE para o ano de 2000 e as capitais incluídas foram Belo Horizonte, Curitiba, Porto Alegre, Recife, Rio de Janeiro, Salvador e São Paulo.

Então, a cartografia racial busca produzir uma representação diferente daquelas que estão nos discursos homogêneos dos estados ou grupos dominantes de elites que insistem na ideia de democracia racial brasileira. A hegemonia aqui tratada demonstra que "o papel da cartografia no exercício das relações de poder favoreceu geralmente as elites sociais" (HARLEY, 2009, p. 5). Denomina-se de cartografia racial a representação e espacialização dos grupos brancos e negros em mapas temáticos, com o intuito de informar ao leitor a concentração ou os distanciamentos produzidos pela localização no espaço urbano. $\mathrm{O}$ mapeamento dos grupos raciais evidencia linguagens e realidades carregadas de diferenciação das relações sociais. Por isso, a cartografia é uma estratégia que se tem atualmente para "revelar um país que nem todos conhecem porque rejeitamos a relação entre etnia, raça e diferenciação espacial” (RATTS, 2011, p. 27).

\section{PERCURSOS METODOLÓGICOS DA CARTOGRAFIA RACIAL}

A motivação para desenvolver a temática da "cartografia racial" foi gerada pelo pressuposto da ocorrência de forte segregação e diferenciação espacial quanto à cor e raça na capital goiana. Nessa direção, buscamos leituras que nos permitissem pensar sistematicamente as relações raciais dentro de um quadro econômico e social nas cidades. A cartografia, como ciência e arte de comunicação, teve papel fundamental na politização dos nossos estudos, ressalta-se isso devido ao seu grande poder de representação, o qual a torna uma representante linguístico-espacial por excelência; portanto, adequada a desmascarar os fenômenos de segregação estudados nessa pesquisa. Por meio da coleta e tratamento de dados estatísticos e de sua integração em um banco de dados, foi possível representar os dados de segregação e diferenciação para a cidade de Goiânia. 
A metodologia dessa investigação contemplou uma revisão teórica em obras que compõem a discussão acerca do tema. Foram pesquisados, além dos trabalhos com grupos raciais no espaço urbano, realizados no âmbito da Geografia, a exemplo de Garcia (2006) ${ }^{1}$, diversos autores das ciências sociais que construíram pesquisas relacionadas a essa abordagem. Pode-se citar trabalhos de sociólogos, como o de França (2010) e obras de demógrafos como a de Rios Neto (2009) e Henriques (2001). É importante ressaltar que essas pesquisas apresentam certas limitações, principalmente no que tange à base de microdados do IBGE, já que esse instituto ainda não possuía a variável cor ou raça no questionário universal.

É necessário refletir acerca de como o IBGE faz a sua autodeclaração nos levantamentos do censo, juntamente com os indicadores sociais contribuintes para o desenvolvimento da pesquisa:

A estrutura classificatória do IBGE para o quesito cor/raça utiliza cinco categorias: branco, preto, amarelo e indígena. Para o órgão, diante da semelhança de comportamentos das estatísticas sociais de pardos e pretos, que permite considerar que sejam resultados da exposição a processos sociais semelhantes, estes podem ser agrupados numa categoria analítica, "negro". "Negro", para o IBGE, portanto, não é uma categoria de cor/raça nas pesquisas, mas sim, a partir da análise dos resultados delas (SANTOS, 2012, p. 50).

A construção da pesquisa partiu principalmente do mapeamento da distribuição populacional da metrópole goianiense, segundo cor ou raça, com os dados do Censo Demográfico (IBGE, 2010) por setor censitário² ${ }^{2}$ No censo (IBGE, 2000), essas informações não apareciam e os dados de cor ou raça ainda eram por amostragem. Nesse último (2010), apareceram no questionário geral, por isso, a disponibilidade e acesso para a espacialização da informação, tornando os dados mais inteligíveis, permitindo a identificação e a representação

\footnotetext{
${ }^{1}$ Neste ponto, é necessário dizer que são poucos os Geógrafos que fazem menção em suas pesquisas a essa temática (RATTS, 2011; SANTOS, R. 2010, 2012), mas existem outras áreas das ciências humanas que estudam essas questões relacionadas à diferenciação de cor, raça e etnia, dentro dos grupos sociais, como a Sociologia (TELLES, 2003; SILVA, 2006).

2 “O setor censitário é a unidade territorial de controle cadastral da coleta, constituída por áreas contíguas, respeitando-se os limites da divisão político-administrativa, do quadro urbano e rural legal e de outras estruturas territoriais de interesse, além dos parâmetros de dimensão mais adequados à operação de coleta” (IBGE, 2010, p.
} 19). 
da distribuição de grupos raciais no espaço. No Sistema de Informações Geográficas (SIGs ArcGIS 10.1) foram reunidos os indicadores sociais, ou seja, as variáveis cor ou raça, associadas ao distrito censitário, e serviram para a construção de mapas temáticos.

Para o tratamento dos dados de cor ou raça, foi utilizado o mesmo critério de classificação de Telles (2003), Paixão (2013) e Garcia (2006). Isso significa dizer que tratamos as seguintes variáveis de cor ou raça: "branco", "negro" (o somatório de "pretos" + "pardos"), "indígenas" e "amarelos". Portanto, não foi mantida a classificação do IBGE (2010) que identifica por cor ou raça os seguintes grupos: "brancos", "pretos", "pardos", "amarelos" e "indígenas".

As metodologias utilizadas pelos autores acima foram embasadas principalmente em Telles (2003), autor que usou os dados do Censo 2000 a partir de técnicas da sociologia norteamericana, comparando como acontece a distribuição de brancos e negros em capitais brasileiras. A unidade espacial utilizada foi a de distrito censitário para distribuir espacialmente cor, raça e renda. Porém, pela dificuldade de se tratar os 1.637 setores censitários para a cidade nos produtos finais, utilizou-se a base do Mapa Urbano Básico Digital de Goiânia (MUBDG), o qual permitiu compatibilizar os limites dos setores censitários com os bairros nos quais estão localizados.

Para a construção dos mapas de cor ou raça, optou-se por trabalhar com dados relativos, os quais permitem discernir quais setores censitários possuem maior quantidade relativa (porcentagem) de brancos ou negros, por exemplo. Para o cálculo dos valores relativos, foi utilizada, em ambiente SIG, a seguinte equação:

\section{$\%$ relativa de brancos do distrito $=$ total de brancos do distrito $\times 100$ /população total do distrito}

A aplicação dessa equação permitiu encontrar os dados relativos que oferecem a possibilidade de encontrar os setores censitários com a maior porcentagem de brancos para Goiânia, aqueles setores em que a população possui população branca igual ou superior a $75 \%$. O mapa de cor ou raça negra foi construído utilizando a mesma lógica:

\section{$\%$ relativa de negros do distrito $=$ total de negros do distrito $\times 100 /$ população total do distrito}

Os setores censitários que possuem porcentagens acima de $75 \%$ de populações residentes que se autodeclararam negras foram considerados Espaços de Maioria Negra, ou 
espaços negros. Ressaltamos que só foram mapeadas as áreas do distrito urbano do município de Goiânia, tanto para os mapas de cor ou raça quanto para os de renda. Para os mapas de cor ou raça foram criadas 4 faixas de intervalo, considerando as diferenças de $25 \%$ de cada. Já para os mapas de renda, de 5 classes, a descrição do esquema é em porcentagens de acordo com as diferenças dos intervalos. Os dados estatísticos foram extraídos do banco de dados da SIDRA $^{3}$, IBGE (2010), tabela (2093), para a variável cor ou raça de população residente de dados absolutos e relativos.

Para os dados de renda foram utilizados os de "domicílios particulares com rendimento mensal domiciliar per capita em salários mínimos" (IBGE, 2010), que equivalem às somas dos rendimentos de todos os moradores de um domicílio. $\mathrm{O}$ salário em reais para $\mathrm{O}$ ano da pesquisa estava em $\mathrm{R}$ \$ 510, 00 (quinhentos e dez reais). A classificação econômica foi feita a partir da divisão por classes do IBGE. O rendimento domiciliar mensal para a classificação das classes econômicas, segundo IBGE (2010), é apresentado na tabela 1, conforme as classes "A", "B", “C”, "D” e "E”.

Tabela 1. Rendimento Mensal Domiciliar da População Brasileira - IBGE (2010)

\begin{tabular}{l|c}
\hline Classe & Renda Média familiar mensal (em reais) \\
\hline A & 14.285 \\
B & 5329 \\
C & 2344 \\
D & 1002 \\
E & 250 \\
\hline
\end{tabular}

Fonte: Censo Demográfico, IBGE, 2010.

Essa classificação gerou as seguintes classes definidas por faixas de rendimento em termos de salários mínimos: "Sem rendimento", a qual não espacializamos, "Extremamente pobre", "Classe baixa", "Classe média baixa", "Classe média alta" e "Classe alta".

Quadro 1. Associação das variáveis de renda por domicílios

\begin{tabular}{|c|c|l|}
\hline CLASSE & $\begin{array}{c}\text { VARIÁVEL } \\
\text { (IBGE) }\end{array}$ & \multicolumn{1}{c|}{ DESCRIÇÃO DA VARIÁVEL } \\
\hline \multirow{2}{*}{ Extremamente } & V005 & $\begin{array}{l}\text { Domicílios particulares com rendimento nominal mensal } \\
\text { domiciliar per capita de até } 1 / 8 \text { salário mínimo }\end{array}$ \\
\cline { 2 - 3 } & V006 & Domicílios particulares com rendimento nominal mensal \\
\hline
\end{tabular}

${ }^{3}$ Disponível: http://www.sidra.ibge.gov.br/bda/tabela/listabl.asp?z=t\&c=2093

4 “Sem rendimento: [...] pessoas em famílias sem rendimentos, sem declaração de rendimentos, pensionistas, empregados domésticos e parentes do empregado doméstico" (IBGE, 2011, p. 115). 


\begin{tabular}{|c|c|l|}
\hline pobre & & domiciliar per capita de mais de 1/8 a 1/4 salário mínimo \\
\hline \multirow{4}{*}{ Classe Baixa } & V007 & $\begin{array}{l}\text { Domicílios particulares com rendimento nominal mensal } \\
\text { domiciliar per capita de mais de 1/4 a 1/2 salário mínimo }\end{array}$ \\
\cline { 2 - 3 } & V008 & $\begin{array}{l}\text { Domicílios particulares com rendimento nominal mensal } \\
\text { domiciliar per capita de mais de 1/2 a 1 salário mínimo }\end{array}$ \\
\cline { 2 - 3 } & V009 & $\begin{array}{l}\text { Domicílios particulares com rendimento nominal mensal } \\
\text { domiciliar per capita de mais de 1 a 2 salários mínimos }\end{array}$ \\
\hline $\begin{array}{c}\text { Classe Média } \\
\text { Baixa }\end{array}$ & V011 & $\begin{array}{l}\text { Domicílios particulares com rendimento nominal mensal } \\
\text { domiciliar per capita de mais de 2 a 3 salários mínimos }\end{array}$ \\
\hline $\begin{array}{c}\text { Classe Média } \\
\text { Alta }\end{array}$ & V012 & $\begin{array}{l}\text { Domicílios particulares com rendimento nominal mensal } \\
\text { domiciliar per capita de mais de 3 a 5 salários mínimos }\end{array}$ \\
\hline $\begin{array}{c}\text { Domicílios particulares com rendimento nominal mensal } \\
\text { domiciliar per capita de mais de 5 a 10 salários mínimos }\end{array}$ \\
Classe Alta & V013 & $\begin{array}{l}\text { Domicílios particulares com rendimento nominal mensal } \\
\text { domiciliar per capita de mais de 10 salários mínimos }\end{array}$ \\
\hline
\end{tabular}

Fonte: Censo Demográfico, IBGE, 2010. Elaborado pelos autores.

Em alguns mapas, o agrupamento de classes ocorre principalmente para evitarmos um número excessivo de mapas em todas as faixas e rendas salariais. O quadro acima apresenta as classes de renda e suas descrições. Alguns desafios foram enfrentados ao buscar certos dados, para isso entramos em contato com os técnicos do IBGE, que auxiliaram bastante e sanaram as dúvidas concernentes aos dados secundários utilizados para a capital goiana.

\section{A CARTOGRAFIA RACIAL EM GOIÂNIA (GO): espaços brancos e espaços negros}

A exemplo de outras grandes cidades, Goiânia apresenta distintos "padrões de ocupação e intensidade urbana" (SOUZA, 2013) que produzem a diferenciação no espaço urbano, visíveis na paisagem da capital, como espaços de centralidades ${ }^{5}$ financiados pelo capital imobiliário e por empresas privadas e outros espaços segregados. A cartografia racial neste trabalho é um instrumento de extrema importância para problematizarmos o lugar dos

\footnotetext{
${ }^{5}$ [...] eles são produzidos para atender certos estratos sociais, conforme determinado padrão de consumo, e geram práticas espaciais novas. Por isso, como resultado não controlado (mais impossível de ser evitado), tanto quanto como condição, alteram o conteúdo social, econômico, político e cultural do centro tradicional. Geram o deslocamento de consumidores que, antes, frequentavam esse setor da cidade, para novos espaços mais modernos, mais bem equipados, com áreas de estacionamento, com prestígio e distinção social, garantindo-lhes centro grau de homogeneidade nos espaços de consumo, que é de matriz, sobretudo, socioeconômica, no caso brasileiro. (SPÓSITO, 2013, p. 76).
} 
grupos raciais na cidade como veremos a partir de agora começando com os mapas de concentração dos grupos brancos em Goiânia.

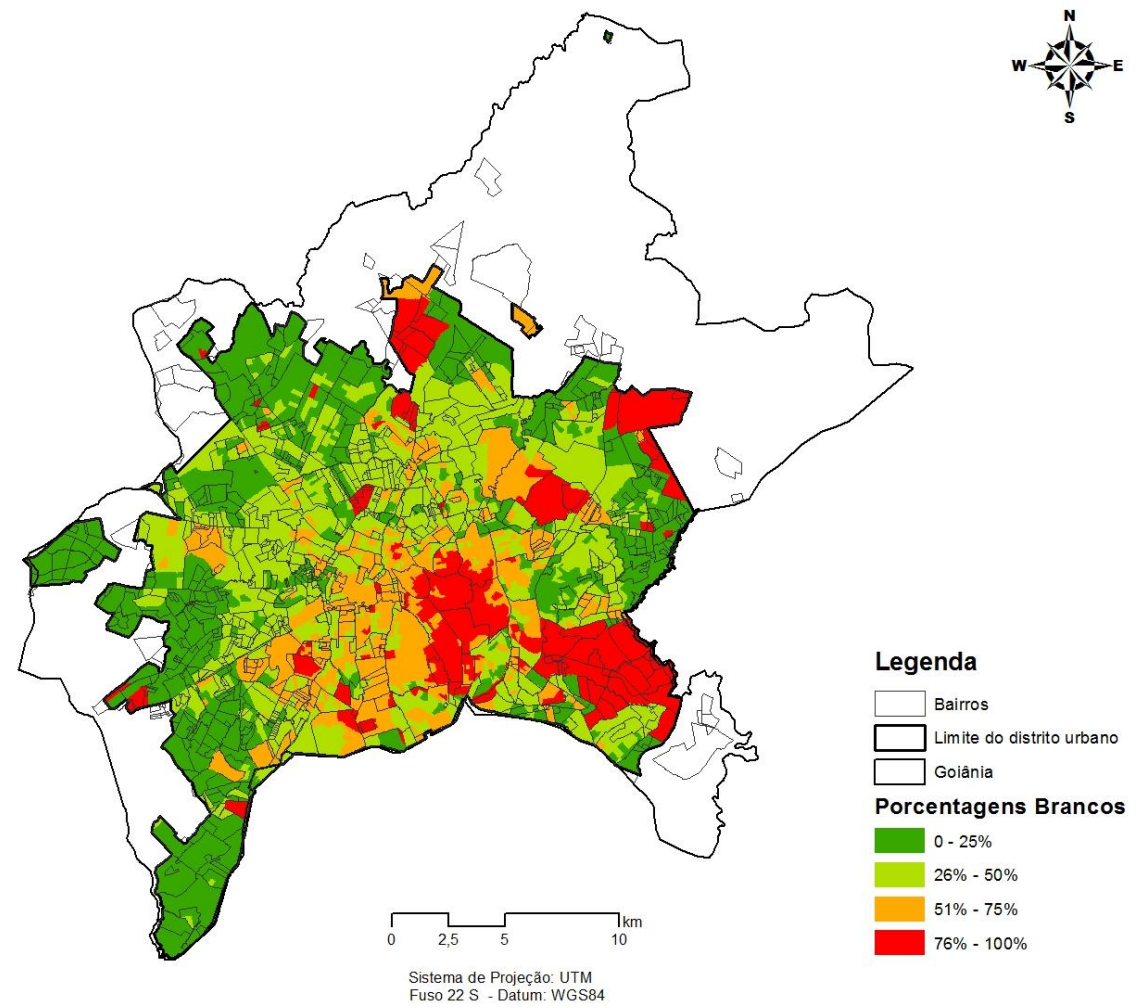

Figura 2 - Concentração de pessoas residentes de cor Branca em Goiânia - 2010.

Fonte: Elaborado pelos autores.

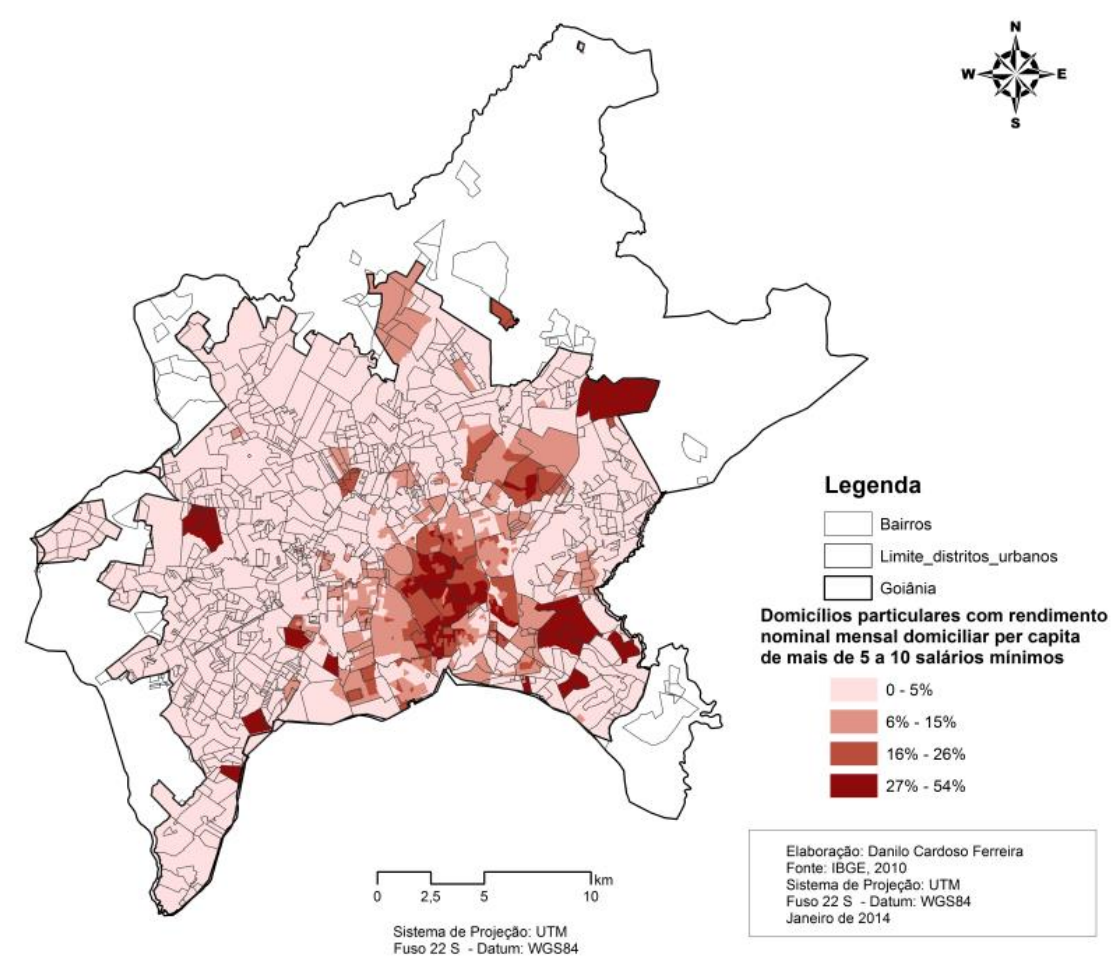


Figura 3 - Concentração de grupos de classe média alta por bairros.

Fonte: Elaborado pelos autores.

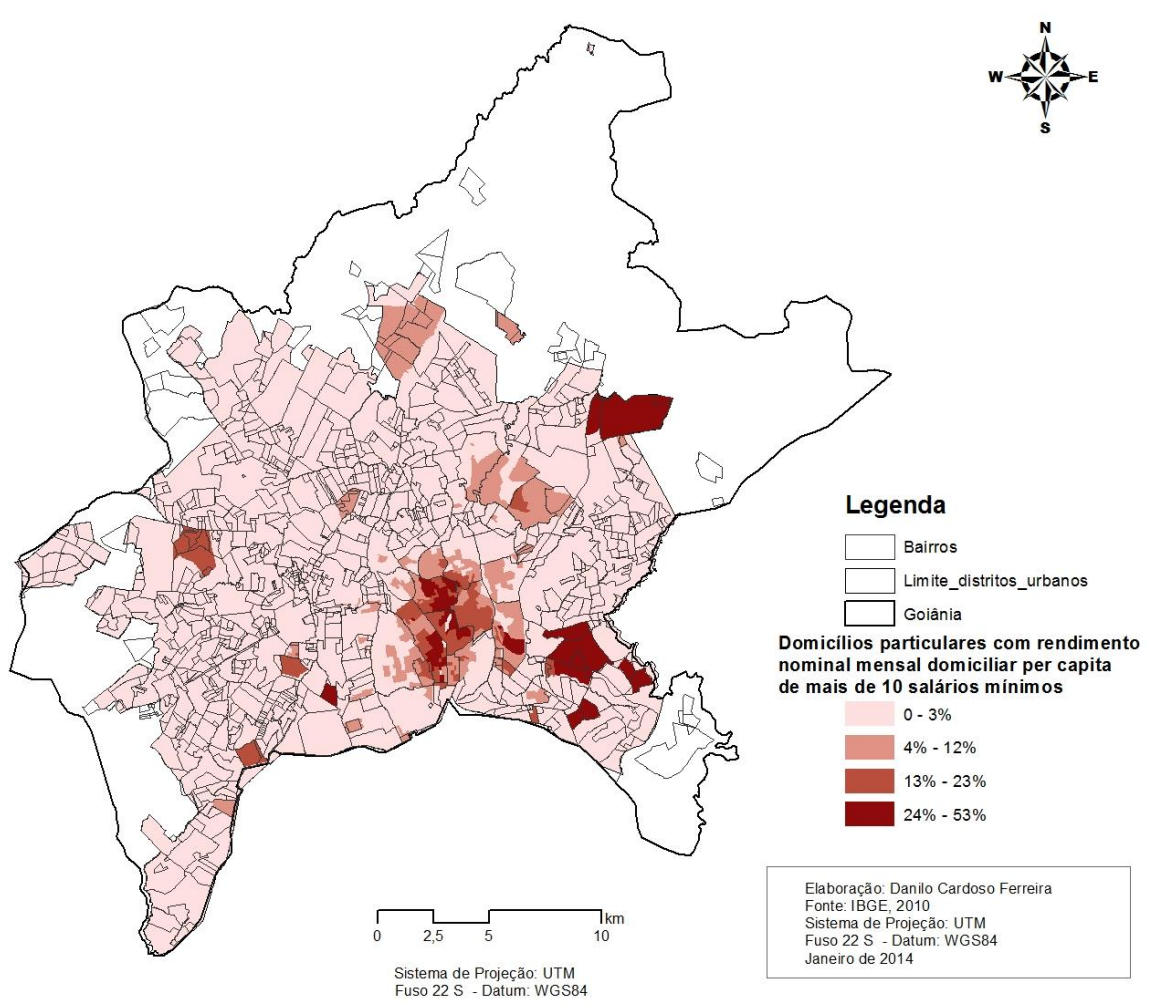

Figura 4 - Concentração de grupos de classe média alta por bairros.

Fonte: Elaborado pelos autores.

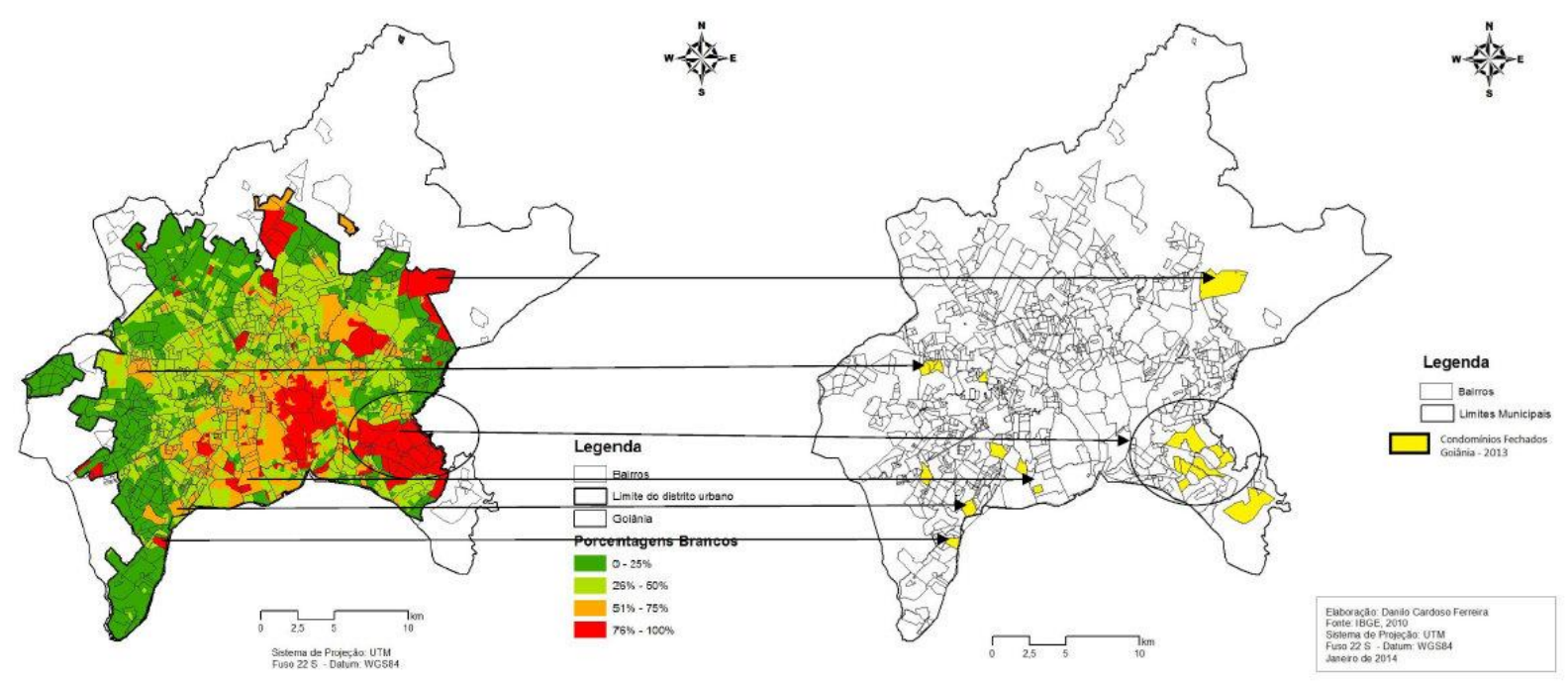

Figura 5. População Residente de Cor branca/E espacialização dos condomínios horizontais em Goiânia - 2010/2013. Fonte: IBGE, Censo Demográfico, 2010; Divisão de Cadastro / DVCAD da SEMDUS, setembro de 2016. Elaborado pelos autores. 
As figuras 2, 3 e 4 nos possibilitam destacar como a faixa de concentração na parte sudoeste, sul, centro e leste da cidade é uma área significativa que poderíamos considerar "espaço branco", na qual se localizam os bairros (setores) Oeste, Marista, Bueno, Jardim Goiás e Setor Central, em que o quantitativo populacional desse segmento representa mais de 92\% do total que ali reside. Esses bairros, a priori, são "espaços abertos" e podem abrigar grupos negros das classes médias, ao contrário dos espaços de maioria negra que são de alta concentração de pobres, como veremos adiante. A figura 5 apresenta a correlação entre os condomínios fechados e as altas concentrações de brancos $(75 \%)$.

Essa mesma figura nos apresenta como há concentração de brancos vivendo nos condomínios fechados na cidade mais desigual economicamente no Brasil, Goiânia. No que diz respeito à média mensal salarial em Goiânia (figura 6), é 31\% maior que a renda mensal média do Brasil, 21\% maior que o índice para a região Centro-Oeste e 35\% maior do que a renda média do Estado de Goiás. Isso indica que a capital goiana está entre as cidades de maiores rendas médias mensais do país, a exemplo de Brasília e São Paulo.

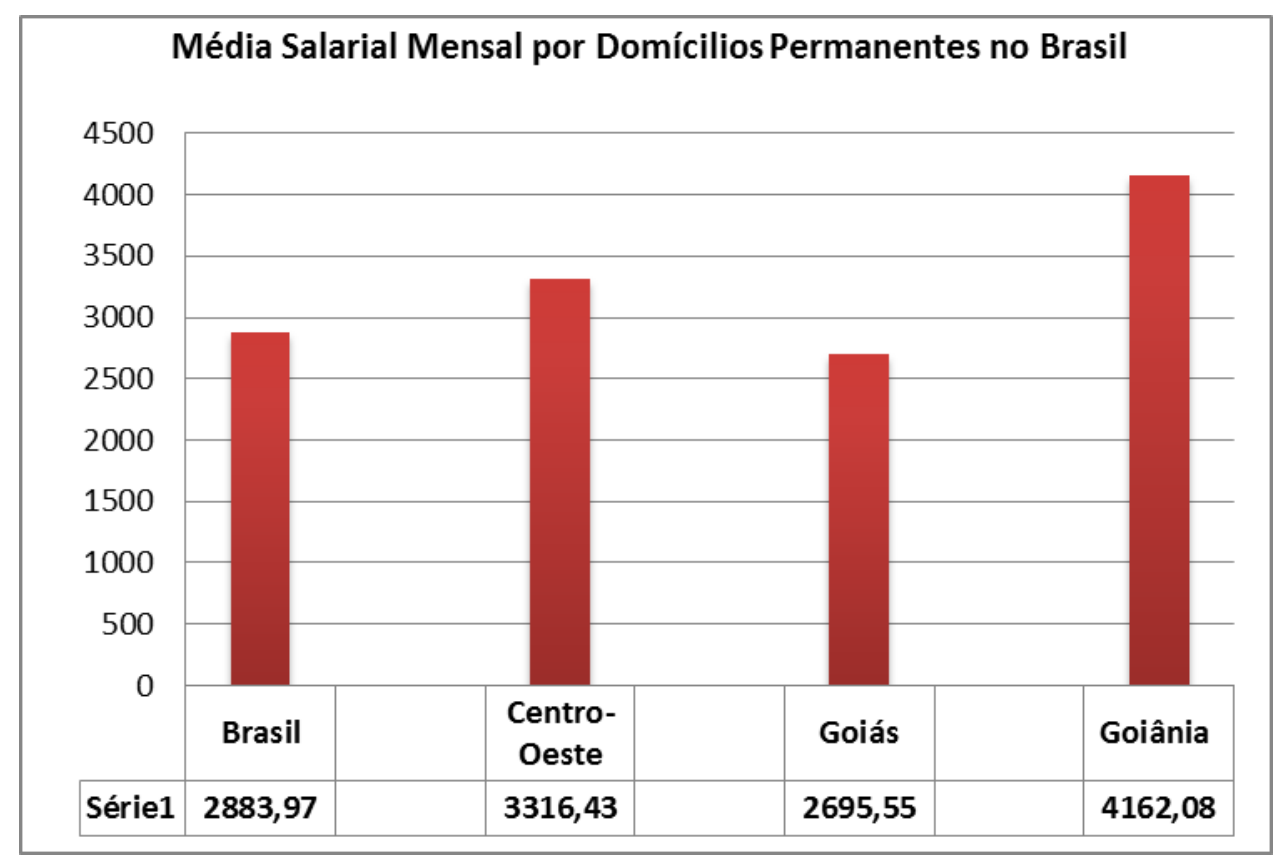

Figura 6. Rendimento mensal mediano dos domicílios particulares permanentes - Goiânia, 2010.

Fonte: IBGE, Censo Demográfico, 2010. Elaborado pelos autores.

Percebe-se pela figura 2, 3 e 4 que os brancos escolhem onde viver, separados espacialmente daqueles que são diferentes de sua cor e também diferentes de sua classe 
econômica. Importante destacar aqui que uma variável não exclui a outra, renda ou raça. Reiteramos que a porcentagem de $75 \%$ é generalizada por questões metodológicas da pesquisa, mas, pontualmente, existem condomínios como Alphaville e Aldeia do Vale que têm acima de $92 \%$ de populações residentes de cor ou raça branca ${ }^{6}$. Esses locais também foram estudados por outros (as) autores (as) na perspectiva da segregação social:

A metrópole goianiense apresenta um número cada vez maior de espaços exclusivos e "elitizados" para se tornarem mais "seguros" para se viver. Essa expansão horizontal com as grandes glebas dos condomínios fechados amplia a expansão dos investimentos e lucros do mercado imobiliário ou até dos limites urbanos, que vai sendo regulada com o beneplácito do Poder Público, pelas legislações sobre o uso e ocupação do solo. A classe médiaalta acompanha esse processo de especulação imobiliária, implicando em uma demanda habitacional e em uma distinção socioespacial (ALMEIDA, 2007, p. 117).

Martins, ao tratar o processo de autossegregação em Goiânia, deixa explícito que morar em condomínios fechados e em regiões periféricas da cidade é uma opção para a população de "classe alta" ou "classe média alta": "Diferentemente do que acontece com as classes mais baixas, que se restringem às áreas mais distantes da cidade por um impedimento econômico claro, o valor da terra, que é mais baixo em relação a outros espaços da cidade" (2014, p. 107).

Os espaços negros (figura 7) cartografados para Goiânia são aqueles com porcentagens acima de $75 \%$ de população negra, não fogem dos padrões apontados por autores como Campos (2006), para Rio de Janeiro; Garcia (2006) para as cidades de Salvador e Rio de Janeiro e França (2010), para São Paulo. Esses estudos indicam que os espaços, territórios e lugares urbanos do segmento negro estão nas áreas periféricas, com baixa infraestrutura urbana e com problemas em relação aos seus domicílios, vivendo em áreas de risco e/ou em aglomerados subnormais.

\footnotetext{
${ }^{6}$ É necessário dizer que estes dois condomínios não estão situados em áreas comerciais como as citadas para a região sul.
} 


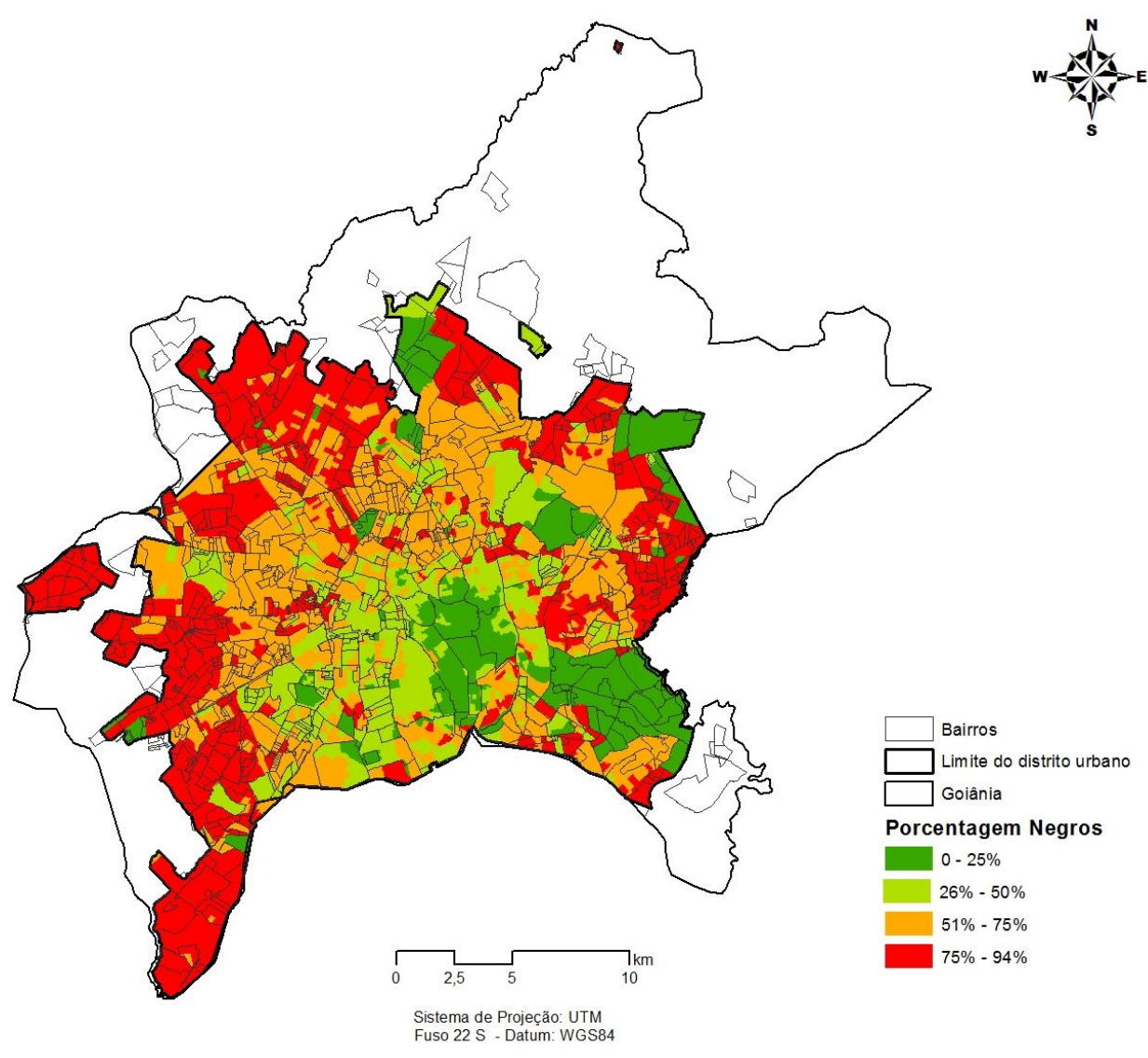

Figura 7 - Concentração de pessoas residentes de cor Negra em Goiânia - 2010. Fonte: Elaborado pelos autores. 


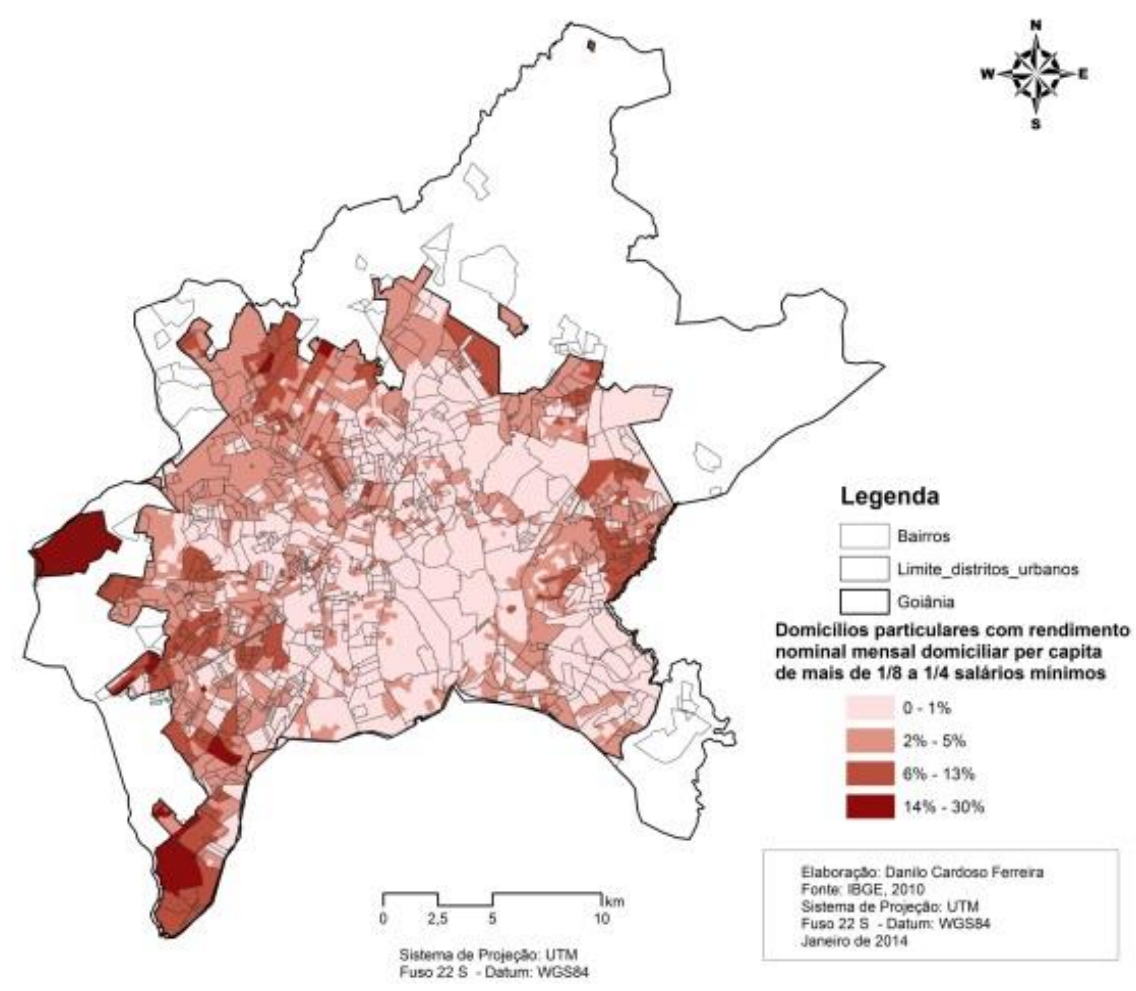

Figura 8 - Concentração de pessoas residentes de "Classe Extremamente Pobre". Fonte: Elaborado pelos autores.

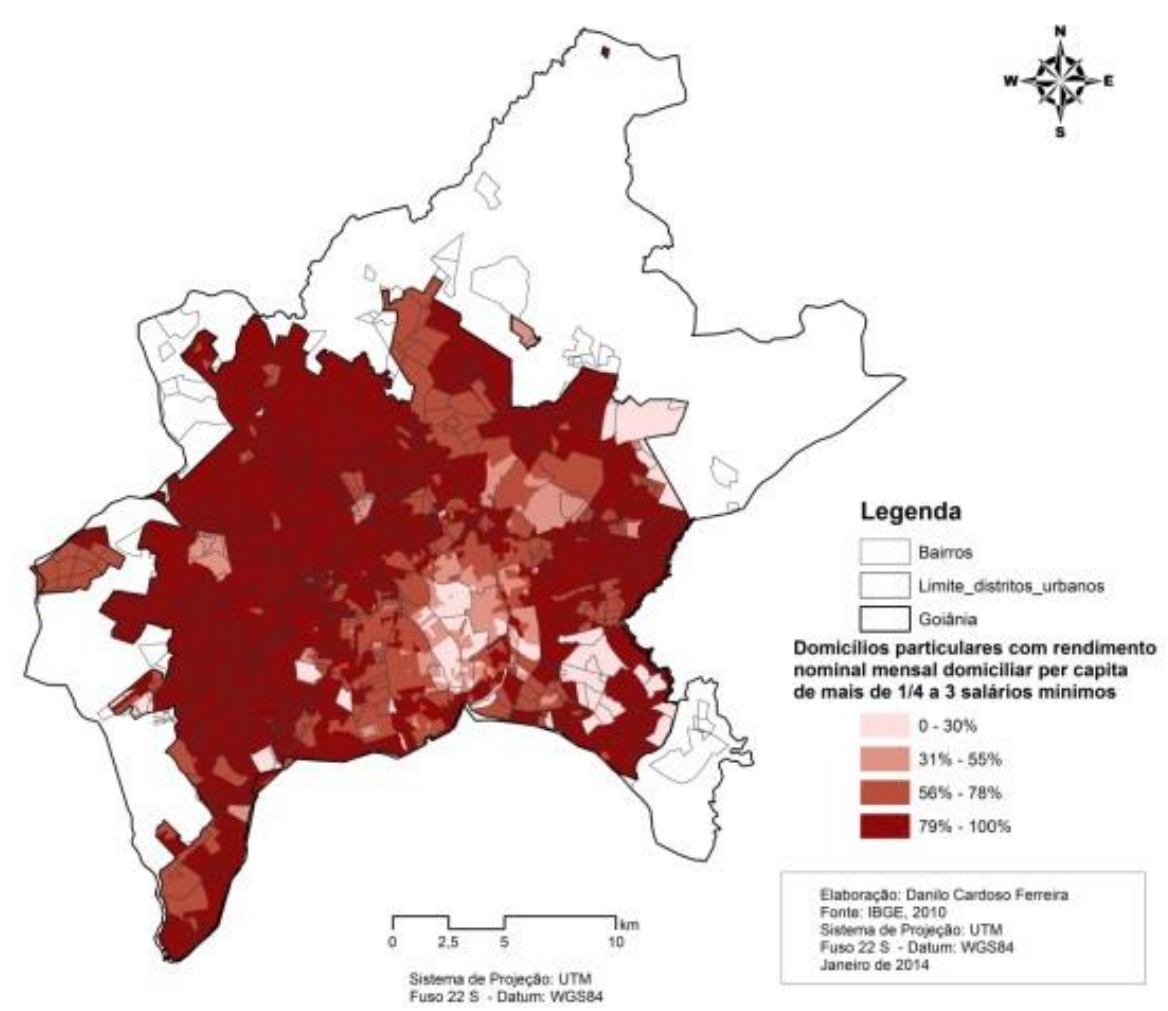

Figura 9 - Concentração de pessoas residentes de "Classe Baixa".

Fonte: Elaborado pelos autores. 


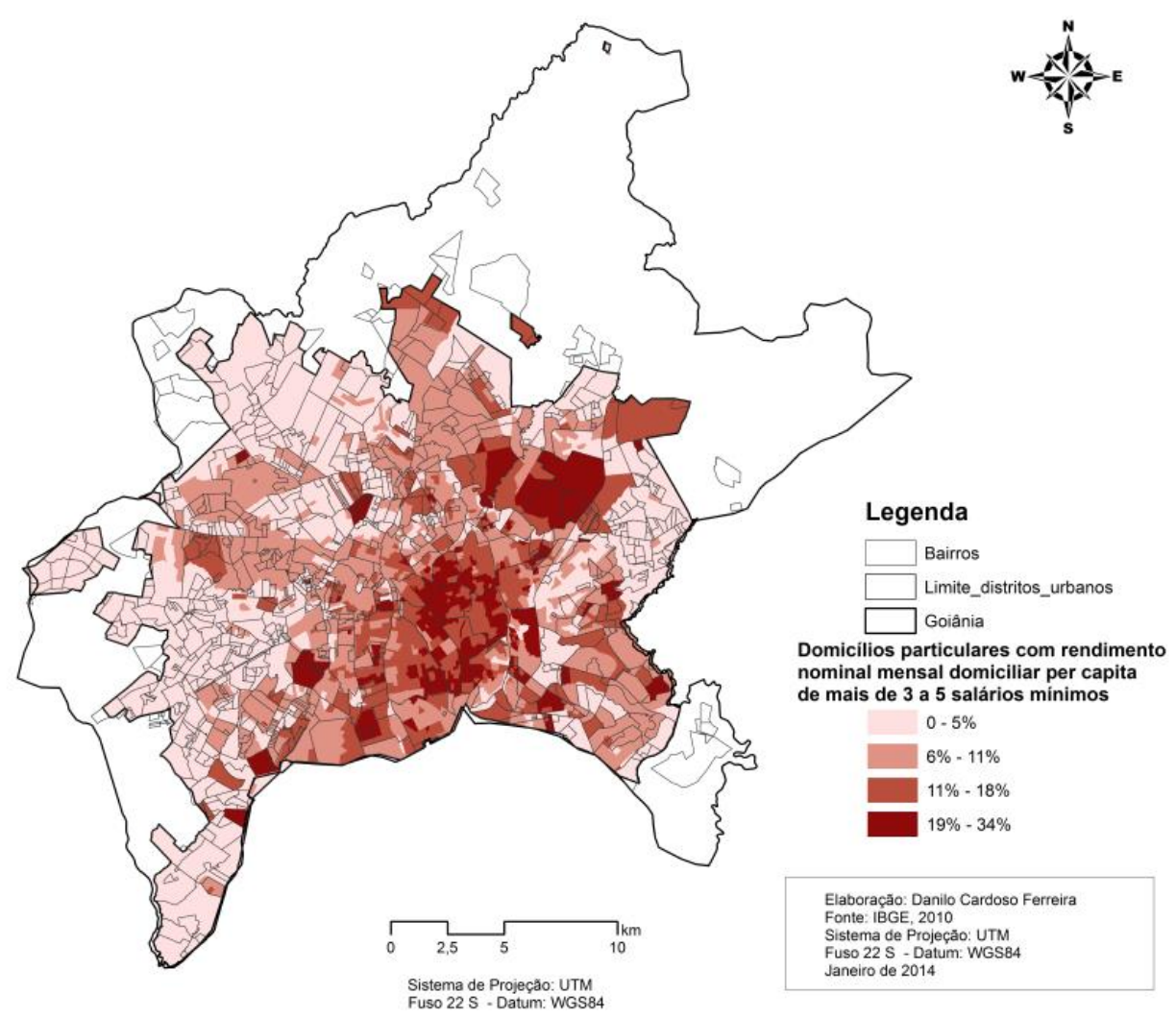

Figura 10 - Concentração de pessoas residentes de "Classe Média Baixa".

Fonte: Elaborado pelos autores.

As figuras 7, 8, 9, 10 justapõe os mapas de concentrações negras com as classes de renda "extremamente pobre", "baixa" e "média baixa". As localizações desses bairros se verificam comumente nas margens da metrópole, em residenciais ou conjuntos habitacionais como na região Oeste, Noroeste e, em alguns casos, no centro de Goiânia.

Cabe destacar que os padrões de urbanização nos bairros de maioria negra estão diretamente associados a lugares com classe de baixa renda e com precárias condições de vida. Associadas a essas questões, pode-se indicar as dificuldades de acessos dos moradores desses bairros ao se deslocarem para o trabalho e outras atividades, de cultura ou lazer, perdendo horas em terminais urbanos.

\section{CONSIDERAÇÕES FINAIS}

A representação da cartografia racial contribuiu para colocar em pauta, mais uma vez, a importância dos mapas como linguagem de comunicação e de entendimento das contradições da sociedade e do espaço, particularmente do espaço urbano. Nesse sentido, 
compreender essas realidades "serve, antes de mais nada, para saber planejar o espaço para poder nele se organizar" (LACOSTE, 2001).

A cartografia racial, então, se torna uma potencialidade para os estudos geográficos de representação e espacialização dos grupos brancos e negros em mapas temáticos, com o intuito de informar ao leitor a concentração ou os distanciamentos produzidos pela localização no espaço urbano. Além de evidenciar, no mapeamento dos grupos raciais, aspectos de linguagem e realidades carregadas de diferenciação nas relações sociais. A cartografia é uma estratégia que se tem atualmente para "revelar um país que nem todos conhecem porque rejeitamos a relação entre etnia, raça e diferenciação espacial” (RATTS, 2011, p. 27).

Diante da cartografia racial podemos concluir que a diferenciação social produz a segregação como um fenômeno espacial. No caso específico deste trabalho, observou-se que, na sociedade brasileira, a diferenciação social, de base econômica, é também racial, particularmente a partir dos principais resultados obtidos para Goiânia, correlacionados ao que foi visto em outras grandes cidades brasileiras. As desigualdades sociais, que também são raciais e se tornam espaciais, contribuem para a reprodução de espaços de grupos semelhantes. Assim, a cartografia acaba por representar a concentração da população negra e branca e os espaços de relativa coexistência. Neles, há agentes hegemônicos da produção e reprodução do espaço, privados ou públicos, em geral, não racializam seu discurso na valorização de determinadas áreas ou no planejamento, com exceção da publicidade de conjuntos residenciais para as classes médias altas e condomínios fechados que trazem corporeidades somente brancas.

Conclui-se que a Geografia, que busca compreender a distribuição espacial dos grupos raciais na cidade, pode contribuir para uma desconstrução do racismo urbano, produzido por uma sociedade de diferenças, desigualdades e de (in)compreensão da divisão racial do espaço. 


\section{REFERÊNCIAS}

ACSELRAD, Henri. Disputas Cartográficas e Disputas Territoriais. In: . (Org.).

Cartografias Sociais e Território. Rio de Janeiro: Universidade Federal do Rio de Janeiro, Instituto de Pesquisa e Planejamento Urbano e Regional, 2008.

ALMEIDA, Rosângela Doin de. Do desenho ao mapa: iniciação cartográfica na escola. 5 eds. São Paulo: Contexto, 2013.

ALMEIDA, Rute Athayde. Olhando a metrópole atrás dos muros. In: PAULA, Flávia Maria de Assis; CAVALCANTI, Lana de Souza. A cidade e seus lugares. Goiânia: E.V., 2007. P. 116-139.

ALONSO, Juan Javier Garcia. Cartografía ambiental. Desarrollo y propuestas de sistematización. Observatorio Medioambiental. Vol. 5. P. 47-78. 2002.

ANJOS, Rafael Sânzio Araújo Dos. Cartografia e Quilombos: territórios étnicos africanos no Brasil. Africana Studia, No 9, P. 337-355. 2006.

BRANDÃO, Carlos Rodrigues. Peões, pretos e congos; trabalho e identidade étnica em Goiás. Brasília, Editora Universidade de Brasília, 1977.

COSTA, Antônio Gilberto; SANTOS, Márcia Maria Duarte. A Cartografia Histórica e a História da Cartografia da América portuguesa e do Brasil Império: Um projeto de difusão do CRCHUFMG. $3^{\circ}$ Simpósio Iberoamericano de História da Cartografia. Agendas para a História da Cartografia Iberoamericana São Paulo, abril de 2010.

FRANÇA, Danilo Sales do Nascimento. Raça, Classe e Segregação Residencial no Município de São Paulo. Dissertação apresentada ao Programa de Pós-Graduação em Sociologia da Faculdade de Filosofia, Letras e Ciências Humanas da Universidade de São Paulo, 2010.

GARCIA, Antônia dos Santos. DESIGUALDADES RACIAIS E SEGREGAÇÃO URBANA EM ANTIGAS CAPITAIS: Salvador, Cidade d' Oxum e Rio de Janeiro, Cidade de Ogum. Tese apresentada ao Curso de Doutorado do Programa de Pós-Graduação em Planejamento Urbano e Regional da Universidade Federal do Rio de Janeiro - UFRJ, 2006.

HARLEY, B. Mapas, saber e poder. In: Confins - Revista Franco-Brasileira de Geografia, $\mathrm{n}^{\circ}$ 5, 2009. Disponível em: http://confins.revues.org/index5724.html.> Acesso: janeiro. 2016.

HENRIQUES. Ricardo. Desigualdade Racial no Brasil: evolução das condições de vida na década de 1990. IPEA: texto 807, Brasília, 2001.

IBGE. Características Gerais da População. Censo Demográfico. Rio de Janeiro, p. 1-178, 2000. Disponível: http://www.ibge.gov.br/home/estatistica/populacao/censo2000/. Acesso: janeiro de 2016.

IBGE. Base de informações do Censo Demográfico 2010: Resultados do Universo por setor censitário. Rio de Janeiro, 2011. Disponível: http://www.censo2010.ibge.gov.br/resultados. Acesso: janeiro de 2016.

IBGE/SIDRA. Sistema IBGE de Recuperação de Recuperação Automática. Rio de Janeiro, 2010. http://www.sidra.ibge.gov.br/. Acesso: janeiro de 2016.

LACOSTE, Yves. A Geografia-Isso serve em primeiro lugar para fazer a guerra. 5 ed. Papirus, 2001.

MARTINELLI, Marcello. As representações gráficas da Geografia: os mapas temáticos. Tese de Livre Docência. São Paulo: USP; FFLCH, 1999.

MARTINS, Rubia Nara Silva. Geotecnologias aplicadas ao estudo de desigualdades socioespaciais no espaço intraurbano goianiense (1991 - 2010). Dissertação de Mestrado apresentada ao Programa de Pesquisa e Pós-graduação em Geografia do Instituto de Estudos Sócio-Ambientais, da Universidade Federal de Goiás, 2014. 
MATIAS, Lindon Fonseca. "Por uma Cartografia Geográfica: uma análise da representação gráfica na Geografia". Dissertação de Mestrado apresentada Programa de Pesquisa e Pós-Graduação da Faculdade de Filosofia, Letras e Ciências Humanas, Universidade de São Paulo, São Paulo, 1996.

OLIVEIRA, Ivanilton José de. Cartografia turística para a fruição do patrimônio natural da Chapada dos Veadeiros (GO). 2008. Tese (Doutorado em Geografia Humana) Faculdade de Filosofia, Letras e Ciências Humanas, Universidade de São Paulo, São Paulo, 2008.

OLIVEIRA, Ivanilton José de; NASCIMENTO, Diego Tarley Ferreira. Mapas da Climatologia, Bases-teórico-metodológicas. Revista da ANPEGE, v. 7, n. 7, p. 127 -141 jan./jul. 2011.

PAIXÃO, Marcelo. 500 anos de solidão: ensaios sobre as desigualdades raciais no Brasil. Curitiba: Appris, 2013.

RATTS, Alex. O negro no Ceará (ou o Ceará negro). In: CUNHA Jr., Henrique, SILVA, Joselina da \& NUNES, Cícera (Org.) Artefatos da cultura negra no Ceará. Fortaleza. Edições UFC, 2011, p. 19 - 40.

RIBEITO, J. F. WALTER, B. M. T.; As Principais Fitofisionomias do Bioma Cerrado. In: Cerrado: Ecologia e Flora. (Org), SANO, S. M.; ALMEIDA, S. P. de.; RIBEIRO, J. F. R.

Embrapa Cerrados. Brasília, DF: Embrapa Informações Tecnológicas, 2008.

RICHTER, Denis. O mapa mental no ensino de Geografia: concepções e propostas para o trabalho docente. São Paulo: Cultura Acadêmica, 2011.

RIOS NETO, Eduardo e RIANI, Juliana de Lucena Ruas. Desigualdades raciais nas condições habitacionais na população urbana. In: SANTOS, Renato Emerson dos (Org.). Diversidade, espaço e relações raciais: O negro na geografia do Brasil. - 3. ed. - Belo Horizonte: Editora Gutenberg, 2009.

ROSA, Roberto. Geotecnologias na Geografia Aplicada. Revista do Departamento de Geografia, 16 (2005) P. 81-90.

SANTOS, Milton. Cidadanias mutiladas. In: CARDOSO, Ruth; KEHL, Maria Rita; BUCCI, Eugênio; DINES, Alberto; OLIVEIRA, Rosiska Darcy de; TELLES, Lygia Fagundes; PIÑON, Nélida; CHAUÍ, Marilena; DALLARI, Dalmo; SANTOS, Milton; KOVADLOFF, Santiago. O preconceito. São Paulo: IMESP, 1996/1997. P. 33 - 44.

SANTOS, Renato Emerson dos. Sobre espacialidades das relações raciais: Raça, racialidade e racismo no espaço urbano. In: SANTOS, Renato Emerson dos (Org.). Questões urbanas e racismo. Petrópolis, RJ: DP et al,.; Brasília, DF: ABPN, 2012.

Ensino de Geografia e Currículo: questões a partir da LEI 10.639. Terra Livre São Paulo/SP Ano 26, V.1, n. 34 p. 141-160. Jan-Jun/2010.

SILVA, Maria Nilza. Nem para todos é a cidade. Segregação urbana e racial em São Paulo. Brasília, DF. Fundação Cultural Palmares, 2006.

SOUZA, Marcelo Lopes de. Semântica urbana e segregação: disputa simbólica e embates políticos na cidade "empresarialista". In: VASCONCELOS, Pedro de Almeida; CORRÊA, Roberto Lobato; PINTAUDI, Silvana Maria (Orgs.). A cidade contemporânea: segregação espacial. São Paulo: Contexto, 2013b. P. 127-145.

SPOSITO, Maria Encarnação Beltrão. Segregação Socioespacial e Centralidade Urbana. In: VASCONCELOS, Pedro de Almeida; CORRÊA, Roberto Lobato; PINTAUDI, Silvana Maria (Org). A cidade contemporânea: Segregação Espacial. São Paulo: Contexto, 2013. P. 6193.

TELLES, Edward. Racismo à brasileira: uma nova perspectiva sociológica. Rio de Janeiro: Relume-Dumará: Fundação Ford, 2003, p.161-184. 